\title{
Travel and Activity Time Allocation: an Empirical Comparison Between Eight Cities in Europe
}

\author{
Charles Raux ${ }^{\mathrm{a}^{*}}$, Tai-Yu Ma ${ }^{\mathrm{a}}$, Iragaël Joly ${ }^{\mathrm{b}}$, Vincent Kaufmann ${ }^{\mathrm{c}}$, Eric Cornelis ${ }^{\mathrm{d}}$, \\ Nicolas Ovtracht ${ }^{\mathrm{a}}$ \\ ${ }^{a}$ Laboratoire d'Economie des Transports (CNRS, Université de Lyon, ENTPE) \\ ${ }^{\mathbf{b}}$ Laboratoire d'Economie Appliquée de Grenoble (INRA, Grenoble-INP) \\ ${ }^{\mathbf{c}}$ Laboratoire de Sociologie Urbaine (EPFL, Lausanne) \\ ${ }^{d}$ Groupe de Recherche sur les Transports (FUNDP, Namur) \\ * corresponding author: email: charles.raux@let.ish-lyon.cnrs.fr, \\ address: LET, ISH, 14 av. Berthelot, 69363 Lyon Cedex 07, France. \\ Phone: +33 472726454, Fax: +33 472726448
}

A previous version of this paper was presented at the 12th International Conference on Travel Behaviour Research, Jaipur, India, December 13-18, 2009. We thank participants in this conference and two anonymous referees for valuable remarks.

\begin{abstract}
A study of daily time allocation to travel and out-of-home activity is conducted across eight European cities over three countries: France (Lyon, Grenoble, Strasbourg and Rennes), Switzerland (Geneva, Bern and Zurich) and Belgium (Brussels), based on individual travel survey data collected between 1997 and 2006. The effects of socio-demographic, spatial context, transport availability and city-specific variables are investigated thanks to the Cox proportional hazard model. The results indicate that socio-demographic characteristics and city (or country) specific effect play a major role while residential density and proximity to high level road or public transport networks have a very limited impact on time budgets for travel and out-of-home activities.
\end{abstract}

Keywords: travel, activity, time allocation, cities, Europe, duration model

Ref : Raux et al Transport Policy.doc - 08 November 2010

Published in Transport Policy 18 (2011) 401-412. http://dx.doi.org/10.1016/j.tranpol.2010.11.004 


\section{Introduction}

Travel and activity time allocation has been a focused issue for regional and transportation science since the 1970's. It has been recognized that individual's daily time allocation results from a complex interaction between socio-demographic characteristics, social rhythms, urban form and transport settings. The observed time allocation pattern reflects individual's spacetime geography, which also differs between societies and cities where people live. One interesting research issue concerns the cross city/national differences on the time allocation behaviour and the related covariate effects.

Although numerous studies have been conducted to investigate the aforementioned effects, the comparative analysis across similar cities is still a less explored area due to the difficulty in the acquisition of data and its cumbersome treatment. Kitamura et al. (1992) compared time use based on the national time use surveys of Netherlands in 1985 and California in 1988. Levinson (1999) analyzed and compared regional time use in the United States. Eurostat (2003) compared mean national time use of twelve European countries. Recent studies in international mobility comparison provide empirical estimates of the effects of explanatory variables on the average travel time and activity duration. Timmermans et al. $(2002,2003)$ have exploited a comparative study of time use pattern across cities in The Netherlands, UK, USA, Canada and Japan based on travel survey data. They investigated the effects of household types, day of week, spatial and transportation characteristics, and cross-national difference on time allocation. They found that the household type, based on predefined sociodemographic groups, and day-of-week effect are highly correlated to the time allocation pattern across different cities. The spatial and transportation settings, however, provide less significant effects on time allocation pattern. The effects of cross-national difference are also less significant than that of socio-demographic characteristics. Although these studies examined the effects of related covariates on the time allocation pattern, the spatial effect, qualified by subjective criteria of urban/suburban and good/poor public transport, still needs more detailed data to investigate its impacts on the time allocation pattern.

Based on previous studies and recently available travel survey data collected in several cities in Europe, our work investigates the effects of the aforementioned covariates on the time allocation pattern across cities. Eight European cities, recognized for their diversity in urban scale and in quality of public transport system, are selected to this end over three countries: France (Lyon, Grenoble, Strasbourg and Rennes), Switzerland (Geneva, Bern and Zurich) and Belgium (Brussels). These data were collected in different periods (1997-2006) through a 24 hours travel diary in all these cities, which provide detailed information on individual's daily time use pattern and related socio-demographic characteristics.

The questions which guided our analysis are the following:

- Weekday time allocation to travel and activities may be influenced by individual socioeconomic factors, spatial context and transport supply, or city/country specificity: what is the relative share of each of these factors in explaining the travel and activity time behaviours?

- Are travel times, considered overall or per activity, dependent on modes used, on spatial context or city specificity?

Unlike previous literature, rather than using predefined socio-demographic groups we analyze the effects of age, gender, work status, presence of children and so on directly at the 
individual level. Also, a specific effort has been achieved in describing the spatial context and the transport supply by using indicators that can be measured with the same method in any city. Overall a lot of checking and harmonization have been carried out in order to make these different sources of data as comparable as possible despite differences of data collection methods and survey questionnaires between countries.

To examine the relative effects of these covariates on the time allocation, the Cox proportional hazard mixture model is applied. Our results show that socio-demographic and city-specific characteristics play a major role while spatial context and transport supply have almost no significant impact on travel time budget and out-of-home activity time budgets.

The organization of the paper is as follows. The description of the data set of these cities and further processing to make them comparable on a common basis are presented in section 2 . In section 3, the Cox proportional hazard mixture model is introduced. The results of analysis are presented and discussed in section 4. Finally, we draw some conclusions.

\section{The data}

The data have been collected through household travel surveys for eight cities across three countries in Europe. It includes Lyon (2006), Grenoble (2002), Rennes (2001) and Strasbourg (1997) in France, Geneva, Bern and Zurich in Switzerland (2000) and Brussels (1999) in Belgium. These cities were selected partly because of the availability of the surveys and their relative contemporaneousness (see Table 1 and Table 2). Moreover, while involving different countries these surveys implement a similar methodology regarding the reporting of travel and activity by the respondents (despite the important and difficult work of harmonisation required for comparison, see below). Last but not least they offer a noticeable diversity in their socio-demographic profile, urban morphology, inner density and transport supply (see Table 3 for a detailed description of the datasets in the eight cities). Thus these various city surveys offer an opportunity to answer the questions expressed above.

As the datasets across these countries differ in terms of survey items and level of details, some common reclassification in terms of travel purposes (activity types), transport modes and socio-demographic characteristics need to be pre-proceeded. As mentioned by Timmermans et al. (2002), international comparative studies usually suffer from similar reclassification problems of dataset in terms of common dependent variables (activity purposes) or explanatory variables (transport mode). Researchers try to make these datasets comparable as possible and avoid utilizing some subjective variables.

To this end, the out-of-home activity types are grouped as 1 work/training, 2 school, 3 shopping/personal business, 4 social-recreation, 5 accompanying. The initial trip purposes can be found in Appendix A. While the identification of "work" or "school" does not raise much difficulty, the difference between shopping/personal business and social-recreation should be regarded cautiously: declaration of the person interviewed, coding by the interviewer and precoding nomenclature, which may differ and be interpreted differently across countries and linguistic areas, interact in the elaboration of the "purpose" of the activity.

The transport modes are reclassified as 1 walk, 2 bicycle, 3 public transport, 4 car, 5 other. Note that in case of a multimodal trip, one main mode is assigned the total travel time for the entire trip according to the following priority: public transport $>$ car $>$ bicycle $>$ walk. Note also that only weekdays (from Monday to Friday) are available in the surveys and thus included in the analysis. This absence of Saturday and Sunday in the surveys is of course a limit regarding shopping and leisure trips. 
Table 1: Characteristics of data set

\begin{tabular}{|c|c|c|c|}
\hline & France & Switzerland & Belgium \\
\hline Title of survey & $\begin{array}{l}\text { Enquêtes-Ménages- } \\
\text { Déplacements } \\
\text { (household travel survey) }\end{array}$ & $\begin{array}{l}\text { Microrecensement } 2000 \\
\text { (microcensus) }\end{array}$ & $\begin{array}{l}\text { Belgian mobility } \\
\text { survey (MOBEL) }\end{array}$ \\
\hline Study year & $\begin{array}{l}1997 \text { (Strasbourg) } \\
2001 \text { (Rennes) } \\
2002 \text { (Grenoble) } \\
2006 \text { (Lyon) }\end{array}$ & 2000 & 1998-1999 \\
\hline $\begin{array}{r}\text { Methodology of } \\
\text { investigation }\end{array}$ & Home-based interview & $\begin{array}{l}\text { Computer assisted telephone } \\
\text { interview (CATI) }\end{array}$ & $\begin{array}{l}\text { Postal survey with } \\
\text { additional follow-up } \\
\text { telephone contact if } \\
\text { necessary }\end{array}$ \\
\hline Respondents & $\begin{array}{l}\text { All individuals of age } \\
\text { over } 5 \text { in the household }\end{array}$ & $\begin{array}{l}\text { one individual of the household of } \\
\text { age over } 6 \text { if the household size is } \\
\text { less than four persons, otherwise } \\
\text { two individuals are studied }\end{array}$ & $\begin{array}{l}\text { All individuals of age } \\
\text { over } 6 \text { in the } \\
\text { household }\end{array}$ \\
\hline $\begin{array}{r}\text { Day when trips are } \\
\text { conducted }\end{array}$ & $\begin{array}{l}\text { All trips conducted the } \\
\text { weekday before the day of } \\
\text { interview }\end{array}$ & $\begin{array}{l}\text { All trips conducted the day or two } \\
\text { days before the day of survey* }\end{array}$ & $\begin{array}{l}\text { All trips conducted } \\
\text { the day before the day } \\
\text { of survey* }\end{array}$ \\
\hline Period of study & $\begin{array}{l}\text { One reference day over } \\
\text { several months out of the } \\
\text { year (October to May) }\end{array}$ & $\begin{array}{l}\text { One reference day over the entire } \\
\text { year }\end{array}$ & $\begin{array}{l}\text { One reference day } \\
\text { over several months } \\
\text { out of the year } \\
\text { (October to May) }\end{array}$ \\
\hline
\end{tabular}

Source: Joly et al. (2007); MOBEL (2009); Office fédéral de la statistique (2001)

* only weekdays have been considered for this study

Table 2: Surface, population and sample per city

\begin{tabular}{lccrrr}
\hline City & $\begin{array}{c}\text { Surface of } \\
\text { survey area } \\
\left(\mathrm{km}^{2}\right)\end{array}$ & $\begin{array}{c}\text { Number of } \\
\text { zones } / \\
\text { municipalities }\end{array}$ & $\begin{array}{c}\text { Average } \\
\text { zone } \\
\text { surface } \\
\left(\mathrm{km}^{2}\right)\end{array}$ & Population & $\begin{array}{c}\text { Number of } \\
\text { individual } \\
\text { in analysis }\end{array}$ \\
\hline Grenoble & 310 & 36 & 8.6 & 386886 & 5864 \\
Rennes & 609 & 46 & 13.2 & 358561 & 8242 \\
Strasbourg & 305 & 32 & 9.5 & 449036 & 4111 \\
Lyon & 490 & 76 & 6.4 & 1226052 & 11703 \\
Brussels & 557 & 33 & 16.9 & 1309478 & 1196 \\
Geneva & 228 & 42 & 5.4 & 410261 & 2071 \\
Bern & 422 & 36 & 11.7 & 333334 & 1458 \\
Zurich & 906 & 99 & 9.2 & 983937 & 2215 \\
\hline
\end{tabular}

The travel time of one trip is calculated as the duration between its arrival time at final destination and departure time. Similarly, the activity duration is approximated as the duration between the departure time of next trip and the arrival time of previous trip. 
Basic data per city on daily overall travel time budget, travel time budget per activity purpose, travel time by trip and mode, and out-of-home activity duration per purpose are given respectively in Appendixes B, C, D and E.

The explanatory variables in travel/activity time budgets analysis include socio-demographic characteristics (gender, age, household type, presence of children and work status). Note that the age variable is reclassified in five segments to include non-linear effects on travel behaviour. Note also that work status doesn't distinguish whether the individual works full time or part time, or works at home for some or all of the time. Unfortunately these potential very important distinctions are not available and this is an obvious limitation.

When it comes to spatial characteristics, municipality-based population residential density is used as an indicator of proximity to facilities, such as shops or other urban amenities, and hence of distance needed to reach these amenities. These data are summed up in the first part of Table 3.

Regarding transport supply, we need to take into account the most relevant characteristics for the individual. The two basic modes have been considered, private car (and of course car ownership by the household) and public transport. Ideally we should consider the accurate choice set offered to the individual (the various modes and their routes, schedules and speeds) in order to perform his/her own activity program (activity locations and schedules). Since we are analysing travel or activity time daily budget we need indicators of transport supply somewhat aggregated in time and space, however suited to the own situation of the individual. Indicators such as city-wide average speed or total public transport supply are too crude from the point of view of actual activity-pattern of the individual. Moreover they would be confounded with fixed city-effect (see below). This is why, as an indirect indicator of potential speed of driving, we use the distance of the individual home to the nearest high speed road infrastructure, here a "divided highway". As regards the quality of public transport supply it stands basically in the frequency of service, reliability and speed. These three characteristics are generally simultaneously improved with rail modes (tramway or light rail, metro or regional train): moreover the presence of such kind of service discriminates locations inside the urban areas, contrary to bus services which are generally available over the whole area. Thus public transport supply is reflected by the distance to the nearest stop of a rail mode as defined above.

The distances are calculated as Euclidean distance between the centre of the zone ${ }^{2}$ where the individual resides and the stations/interchanges of rail/road network. Based on these common definitions these distances have been computed by the different research teams in their countries. Overall the data from different cities have been provided by the different teams and processed centrally by the LET team. A summary of characteristics of transport supply is given in the second part of Table 3 .

Regarding these distances, a self-selection issue may arise, since for instance households may choose their residential location based partly on their preferences for travel time budget or mode use. We have used the available rich socio-demographic data, on a disaggregate basis (i.e. these are individual data, not based on zone average). Income is not available (because of absence in survey or high level of non-response) but in European cities income variable is not found to be a major determinant of location and travel choices of households. Richer people

\footnotetext{
${ }^{1}$ Divided highway is defined as a road or highway in which the two directions of traffic are separated by a central barrier or strip of land without direct access (neither stops, nor traffic lights).

${ }^{2}$ using the finest zoning available: the location of household is only available on a zone basis.
} 
may live just as well in city centre to benefit from urban amenities as in the outskirts to benefit from larger housing and environmental amenities. Moreover its impact on travel behaviour is captured through automobile equipment which is controlled in our data by the inclusion of car ownership. So, subject to the hypothesis that these socio-demographic variables account for the difference in individuals, our study is little affected by this selfselection issue.

The issue of "modifiable areal unit problem" (MAUP; Openshaw, 1984), which involves both a scale effect and an aggregation effect (or "zonation" effect), arises since it may affect our spatial variables (density and distances to transport supply). As for the scale effect, Table 2 indicates that the average zone surfaces are roughly of the same order of magnitude among the various cities: thus this effect should be limited either for density or for distance variables. As for the aggregation effect, density is little influenced by alternative zoning for a given scale. This is clearly not the case for distances to transport supply. However, since we are comparing overall 400 zones across the eight cities, each with its own zoning, a reasonable assumption is that the zoning does not produce any bias in distances to transport supply. 
Table 3: Definition and descriptive statistics of covariates in terms of individual's socio-demographic, spatial and transport availability characteristics

\begin{tabular}{|c|c|c|c|c|c|c|c|c|c|}
\hline Covariates & Definition & Grenoble & Rennes & Strasbourg & Lyon & Brussels & Geneva & Bern & Zurich \\
\hline \multicolumn{10}{|c|}{ Socio-demographic characteristics } \\
\hline Male & Gender ( 1 if male, 0 female) $(\%$ of 1$)$ & 49.3 & 46.5 & 47.5 & 48.7 & 48.2 & 45.7 & 43.4 & 48.1 \\
\hline Age $<15$ & 1 if the age of the individual is under 15 ( $\%$ of 1$)$ & 13.5 & 15.5 & 14.8 & 15.7 & 13.0 & 9.1 & 6.7 & 9.6 \\
\hline Age15_25 & 1 if the age of the individual is within $[15,25)(\%$ of 1$)$ & 21.2 & 19.8 & 17.9 & 12.8 & 12.3 & 9.0 & 8.1 & 9.5 \\
\hline Age25_55 & 1 if the age of the individual is within $[25,55)(\%$ of 1$)$ & 45.0 & 47.6 & 48.3 & 45.3 & 51.3 & 50.4 & 46.0 & 45.3 \\
\hline Age55_65 & 1 if the age of the individual is within $[55,65)(\%$ of 1$)$ & 9.6 & 8.3 & 9.4 & 11.8 & 9.5 & 14.7 & 15.1 & 15.1 \\
\hline Age $\geq 65$ & 1 if the age of the individual is 65 or over $(\%$ of 1$)$ & 10.8 & 9.0 & 9.7 & 14.4 & 13.9 & 16.8 & 24.2 & 20.5 \\
\hline Couple & 1 if couple $(\%$ of 1$)$ & 75.0 & 75.6 & 78.6 & 78.6 & 23.9 & 62.9 & 61.7 & 64.8 \\
\hline Children_12 & 1 if children under 12 are present in the household ( $\%$ of 1$)$ & 26.1 & 36.2 & 36.2 & 35.7 & 33.2 & 23.1 & 16.2 & 20.6 \\
\hline Work_status & Employment status ( 1 have a job) (\% of 1$)$ & 43.0 & 59.8 & 46.1 & 46.6 & 50.1 & 57.1 & 56.8 & 57.1 \\
\hline \multicolumn{10}{|c|}{ Spatial and transport availability characteristics } \\
\hline Dist_interchange & Distance to the nearest interchange of divided highway $(\mathrm{km})$ (mean) & 1.6 & 2.0 & 2.0 & 1.9 & 2.6 & 2.0 & 2.0 & 2.2 \\
\hline Dist_PT & Distance to the nearest station of metro or tramway $(\mathrm{km})$ (mean) & 1.6 & 2.4 & 1.6 & 1.5 & 0.4 & 1.0 & 0.4 & 0.5 \\
\hline Car_ownership & 1 if car is available in the household ( $\%$ of 1$)$ & 86.5 & 90.2 & 84.8 & 88.1 & 83.6 & 79.9 & 70.8 & 76.9 \\
\hline Density & Population density of municipality of residence (persons $/ \mathrm{km}^{2}$ ) (mean) & 1248.0 & 588.8 & 1472.2 & 2502.1 & 2350.9 & 1799.4 & 789.9 & 1086.0 \\
\hline
\end{tabular}




\section{The model}

The main objective of this study is to assess the effects of explanatory variables on the duration of trips and activities across these European cities. Our application questions the determinants of individual's daily travel time budget and trip duration to various activities. To this end, we consider the methods deriving from survival analysis, which in general aims to investigate failure time distributions and assess the effects of influence factors.

In order to examine the relative effects of these covariates on time allocation, the Cox proportional hazard model (called Cox PH model hereafter) is applied. The advantage of the Cox PH model is that it needs not to specify the baseline hazard function and can incorporate the covariates of interest. We present here a short introduction of applied methods for this purpose. Detailed descriptions of applied methods and related applications can be found in Kalbfleisch and Prentice (2002).

Let $T$ be a nonnegative continuous random variable representing the failure time of a process or the duration of the process. The survival function $S(t)$ is defined as the complement of the cumulative probability distribution function:

$S(t)=\int_{t}^{\infty} f(u) d u$

where $f(t)$ is the density function of failure time $T$. We are particularly interested in the estimation of hazard function $\lambda(t)$, defined as:

$\lambda(t)=\lim _{h \rightarrow 0} \frac{P(t \leq T<t+h \mid T \geq t)}{h}$

The hazard function represents the instantaneous rate of failure of the process at time $t$ given that the process has lasted until time $t$. Based on the above hazard function, the density function can be written as:

$$
f(t)=\lambda(t) S(t)
$$

For the above hazard function specification, parametric, non-parametric or semi-parametric methods may be applied. The parametric model specification tries to fit the duration data to some usual parametric probability distribution, such as exponential, Weibull, or gamma distribution. Previous empirical studies have shown that the profile of travel/activity duration hazard is generally irregular and with multiple spikes (Ma et al., 2009). As we are interested in investigating the effects of covariates on duration data, semi-parametric models (also called Cox models) are preferred. Cox PH model is estimated using the partial likelihood framework suggested by Cox (1972), which does not need the specification of the baseline hazard function $\lambda_{0}(t)$. One avoids then the risk of a misspecified baseline hazard function. The quality of the estimation of the covariates coefficients is considered to be more robust than the fully-parametric approach (Oakes, 1977).

The Cox PH model is specified as:

$$
\lambda(t \mid \mathbf{X})=\lambda_{0}(t) \exp \left(\mathbf{X}^{\prime} \boldsymbol{\beta}\right)
$$


where $\lambda_{0}(t)$ denotes the baseline hazard function for failure time $t, \mathbf{X}$ and $\boldsymbol{\beta}$ the column vectors of covariates and regression coefficients, respectively .

The above model specification assumes that the effects of covariates on duration hazard are multiplicative. Hence each individual hazard is proportional with respect to the baseline hazard. Separation of the time effect and the covariate effect leads to the proportional hazard assumption with respect to each covariate by keeping the values of other covariates constant. The relative risk between individual $i$ and $j$ is the ratio of hazards:

$$
\frac{\lambda_{i}(t)}{\lambda_{j}(t)}=\frac{\lambda_{0}(t) \cdot \exp \left\{X_{i} \beta\right\}}{\lambda_{0}(t) \cdot \exp \left\{X_{j} \beta\right\}}=\exp \left\{\left(X_{i}-X_{j}\right) \beta\right\}
$$

Hence, the hazards of two individuals are proportional with respect to their related covariate values.

However, ignoring the sample selection issue (i.e. engaging or not in an out-of-home activity) will lead to biased parameters (Bhat, 1996). The model needs to take into account whether the event of interest occurs (i.e. "incidence") and given that it occurs its duration (i.e. "latency"). This problem is similar to those dealt with in clinical trials with "mixture cure models". Following Corbière and Joly (2007), let $U$ be the indicator denoting an individual is susceptible $(U=1)$ or non-susceptible $(U=0)$ to engage in the activity and $T$ is a nonnegative random variable denoting the failure time, defined only when $U=1$. The mixture cure model is given by

$$
S(t \mid x, z)=\pi(z) S(t \mid U=1, x)+1-\pi(z)
$$

where $S(t \mid x, z)$ is the unconditional survival function of $T$ for the entire population, $\pi(z)=P(U=1 \mid z)$ is the probability to engage in the activity given the covariate vector $z$, $S(t \mid U=1, x)=P(T>t \mid U=1, x)$ is the survival function for "engaged" individuals given the covariate vector $x . \pi(\mathrm{t})$ is modelled using a binary logit model.

Simultaneous estimation of the individual probability of engagement in out-of-home activity (with a logit model) and the duration of activity for those engaged (with a Cox PH model) relies on the SAS macro for semiparametric mixture model proposed by Corbière and Joly. The reader is referred to this paper for detailed description of the estimation procedure and the SAS macro, which performs simultaneous maximisation of both the likelihood of the logit model and the Cox's partial-likelihood of the duration PH model, using EM algorithm.

When interpreting the results of Cox PH models, it should be noted that a positive regression coefficient means a greater risk of stopping travel/activity, i.e. a shorter travel/activity time budget, while a negative regression coefficient means a longer travel/activity time budget.

\section{Results and discussion}

In this section, we address successively the two research questions referred to in the introduction, that is to say weekday time allocation to travel and activities, and travel times per activity. 


\subsection{Time allocation to travel and main out-of-home activities}

We present here the duration analysis with respect to individual's travel time budget and activity time budgets per day. The travel time budget is defined as the summation of durations of trips conducted in 24 hours. Similarly, the activity time budget is calculated by the summation of durations of activities of the same type conducted during the 24 hours period.

For the covariate settings, the socio-demographic, spatial and transport availability covariates are included in the duration model (Table 4). City fixed effects are added and specified as dummy variables to investigate their effects on aforementioned duration data. Moreover, the survey methodology is expected to influence the measurements. Grossly speaking, there is one common methodology in each of the three countries, i.e. common to the four French cities on the one hand, and for the three Swiss cities on the other hand. For Belgium we have only the Brussels city, so this methodology effect is confounded with the city-effect. By analyzing either the French cities or the Swiss cities on a whole we can detect such methodology effect. It should be noted that this includes not only the survey methodology effect but also other effects specific to the country such as those relating to way-of-life, culture and so on.

\subsubsection{Daily travel time budget}

The Cox PH mixture model estimation results of daily travel time budget are shown in Table $4\left(1^{\text {st }}\right.$ column for logit model and $2^{\text {nd }}$ column for Cox PH model).

Engagement in out-of-home activities (i.e. non zero travel time budget) is higher for male, for adults between 15 and 65 when compared with adults over 65 (and lower for youngsters under 15), very high for workers, and lower for those living in couple or when children under 12 are present in the household. Socio-demographic factors have expected effects. Engagement in out-of-home activities is also higher when car is available in the household. Regarding cities, only in Rennes a significant lower propensity to engage in out-of-home activity appears.

Regarding travel time budget socio-demographic factors have also expected effects (see Mokhtarian and Chen (2004) and Joly (2006) for reviews of studies on daily travel time): males have a longer travel time budget compared with females, younger people (under 15) have a shorter travel time budget when compared with adults over 65 , while other between 15 and 65 have a longer travel time budget. The presence of children under 12 or living in couple induces a shorter travel time budget.

As for the impact of spatial context and transport mode availability, it is interesting to note that there is no effect of car ownership, density and distance to public transport on travel time budget. Only a greater distance to major highway has a slight effect of increasing travel time budget (the hazard is reduced by less than $2 \%$ ).

Regarding city-specific effects, the results indicate that people living in the French city of Lyon and the Swiss cities of Geneva and Zurich have longer travel time budgets, while it is the opposite for the French city of Rennes. Considering the opposite effects in France, this indicates no France's specific effect but perhaps one for Switzerland.

The results of daily activity time budgets model for each of activity purposes are also shown in Table 4. We fit a Cox PH mixture model for each of activity purposes. School activity (and therefore accompanying activity) time budget is excluded from the analysis since the duration of this activity is largely determined by exogenous societal rhythms. The estimation results are discussed below for each of activity purposes. 


\subsubsection{Daily work/training (out-of-home) time budget}

Regarding engagement in work activity, it should be noted that only individuals with full or part-time working status (whether they work at home or not) are included in this model. Thus given the various days of the week when the survey occurs, these people may or may not engage in out-of-home work activity. The probability is higher for males and for individuals between 15 and 65 when compared with those over 65, and lower when being in couple or when young children are present in the household. These socio-demographic effects are as expected, whereas there is neither significant effect of spatial and transport characteristics nor of city.

When it comes to work daily time budget, here again socio-demographic factors have expected effects: male people have longer work time budget as well as the central age categories (over 15 and under 65). Being in couple or the presence of children under 12 induce shorter work time budget.

Car ownership is associated with longer work daily duration, while it is the opposite for the distance to public transport. Density and distance to major highway have no significant effect. When compared with Brussels, people living in the French and Swiss cities have longer work time budget, with a much higher effect in Bern and Zurich when compared with Geneva and then to the French cities. Perhaps is there a cultural and/or linguistic area effect.

\subsubsection{Daily shopping or personal business time budget}

As for engagement in shopping or personal business out-of-home activities, the logit model indicates a lower engagement for males, and youngsters and adults when compared with people over 65 , and also a negative effect of being in couple, having young children at home or being a worker. While distance to public transport has also a negative effect as expected, density has too, which is somewhat unexpected. Living in Rennes, Strasbourg, Bern or Zurich has a positive effect on engagement while it is the opposite for Lyon. This probably indicates local factors not taken into account by our covariates.

Regarding shopping and personal business time budget, the results indicate that couples have a slightly higher activity time budget, but the presence of children under 12 has inverse effect. People over 25 and under 65 have longer activity time budget. Also, workers spend less time on shopping or personal business activity, probably due to less available time for their personal use.

Spatial and transport availability characteristics play no significant role for shopping and personal business activity time budget. City-specific effects indicate that in all French and Swiss cities (but at a lesser degree in Lyon) people spend less time on shopping and personal business when compared with Brussels. 
Table 4: Cox PH mixture models for daily travel and activity time budgets

\begin{tabular}{|c|c|c|c|c|c|c|c|c|}
\hline \multirow[b]{2}{*}{ Model } & \multicolumn{2}{|c|}{ Travel time budget } & \multicolumn{2}{|c|}{ Work time budget } & \multicolumn{2}{|c|}{$\begin{array}{l}\text { Shopping / Personal } \\
\text { business time budget }\end{array}$} & \multicolumn{2}{|c|}{$\begin{array}{c}\text { Social-Recreation time } \\
\text { budget }\end{array}$} \\
\hline & Logit & $\mathrm{Cox} \mathrm{PH}$ & Logit & $\mathrm{Cox} \mathrm{PH}$ & Logit & $\mathrm{Cox} \mathrm{PH}$ & Logit & $\mathrm{Cox} \mathrm{PH}$ \\
\hline Intercept & $4.925 * * *$ & & 2.055 & & $8.254 * * *$ & & $7.192 * * *$ & \\
\hline \multicolumn{9}{|c|}{ Socio-demographic characteristics } \\
\hline Gender & $0.239 * *$ & $-0.105 * * *$ & $1.523 * * *$ & $-0.374 * * *$ & $-0.571 * * *$ & 0.022 & 0.357 & $-0.041^{* *}$ \\
\hline Age $<15$ & $-1.027 * * *$ & $0.442 * * *$ & n.a. & n.a. & $-6.513 * * *$ & $0.099 * *$ & $-2.233 *$ & $0.110 * * *$ \\
\hline Age15_25 & $4.580 * * *$ & $-0.319 * * *$ & $2.049 * * *$ & $-0.446^{* * *}$ & $-4.450 * * *$ & 0.0125 & 1.157 & $0.075 * *$ \\
\hline Age25_55 & $2.344 * * *$ & $-0.283 * * *$ & $6.897 * * *$ & $-0.496 * * *$ & $-2.338 * * *$ & $-0.122 * * *$ & -0.773 & $0.091 * * *$ \\
\hline Age55_65 & $1.183^{* * *}$ & $-0.162 * * *$ & $4.107 * * *$ & $-0.478 * * *$ & $-1.265^{* *}$ & $-0.138 * * *$ & -0.391 & 0.021 \\
\hline Age $\geq 65$ & ref. & ref. & ref. & ref. & ref. & ref. & ref. & ref. \\
\hline Couple & $-0.985 * * *$ & $0.039 * * *$ & $-1.556^{* *}$ & $0.060 * * *$ & $-0.601 * * *$ & $-0.077 * * *$ & $-1.768 * * *$ & $0.150 * * *$ \\
\hline Children_12 & $-0.688 * * *$ & $0.042 * * *$ & $-1.814^{* * *}$ & $0.080 * * *$ & $-0.334 * * *$ & $0.063 * * *$ & $-2.385 * * *$ & $0.141 * * *$ \\
\hline Work_status & $6.425^{* * *} *$ & 0.005 & n.a. & n.a. & $-0.395 * * *$ & $0.220 * * *$ & $1.150 * * *$ & $0.247 * * *$ \\
\hline \multicolumn{9}{|c|}{ Spatial and transport availability characteristics } \\
\hline Car_ownership & $1.212 * * *$ & -0.019 & 0.409 & $-0.170 * * *$ & 0.0057 & -0.0315 & $2.134 * * *$ & 0.001 \\
\hline Density & $-0.047 *$ & $-0.003 *$ & 0.077 & 0.002 & $-0.020 * *$ & $0.006 *$ & $-0.075^{*}$ & -0.010 \\
\hline Dist_PT & -0.030 & -0.004 & 0.003 & $0.025 * * *$ & $-0.089 * * *$ & 0.0072 & $-0.228 * * *$ & $-0.015^{* *}$ \\
\hline Dist_interchange & 0.084 & $-0.014 * * *$ & 0.130 & -0.0003 & -0.006 & 0.0004 & $0.456^{* * *}$ & 0.004 \\
\hline \multicolumn{9}{|c|}{ City-specific variables } \\
\hline Grenoble & 0.272 & -0.020 & 4.640 & $-0.139 * *$ & 0.180 & $0.143 * * *$ & $3.595 * * *$ & $0.178 * * *$ \\
\hline Rennes & $-1.277 * * *$ & $0.143 * * *$ & -0.541 & $-0.188 * * *$ & $0.340 * *$ & $0.179 * * *$ & $1.091^{*}$ & $0.161 * * *$ \\
\hline Strasbourg & -0.228 & -0.030 & 3.707 & $-0.148^{* *}$ & $0.366^{* *}$ & $0.236 * * *$ & $2.010 * * *$ & $0.109 *$ \\
\hline Lyon & 0.047 & $-0.08 * * *$ & 3.178 & $-0.199 * * *$ & $-0.397 * *$ & $0.096 *$ & $1.015^{*}$ & $0.152 * * *$ \\
\hline Geneva & 0.345 & $-0.109 * * *$ & 1.496 & $-0.283 * * *$ & 0.038 & $0.133 * * *$ & 5.717 & $0.108 *$ \\
\hline Bern & -0.064 & $-0.073^{*}$ & 0.499 & $-0.453 * * *$ & $0.859 * * *$ & $0.237 * * *$ & 4.992 & 0.0826 \\
\hline Zurich & 0.794 & $-0.177 * * *$ & 0.911 & $-0.526 * * *$ & $0.651 * * *$ & $0.230 * * *$ & 6.267 & $0.109 *$ \\
\hline Brussels & ref. & ref. & ref. & ref. & ref. & ref. & ref. & ref. \\
\hline \multicolumn{9}{|l|}{ Models fit statistics } \\
\hline Sample size & 36860 & 30267 & 15651 & 11400 & 36860 & 12652 & 36860 & 12050 \\
\hline Log-likelihood & -15129.10 & -280987.44 & $-8758,36$ & $-94805,26$ & -21507.19 & -106754.36 & -22639.84 & -100969.37 \\
\hline Total log-likelihood & \multicolumn{2}{|c|}{-296116.54} & \multicolumn{2}{|c|}{$-103563,62$} & \multicolumn{2}{|c|}{-128261.55} & \multicolumn{2}{|c|}{-123609.21} \\
\hline $\begin{array}{l}\text { Likelihood ratio } \\
\text { (df) }\end{array}$ & \multicolumn{2}{|c|}{$\begin{array}{l}6426.98 * * * \\
(19)\end{array}$} & \multicolumn{2}{|c|}{$\begin{array}{l}1355,62 * * * \\
(17)\end{array}$} & \multicolumn{2}{|c|}{$\begin{array}{l}4608.95^{* * *} \\
(19)\end{array}$} & \multicolumn{2}{|c|}{$\begin{array}{c}1745.04 * * * \\
(19)\end{array}$} \\
\hline
\end{tabular}

\subsubsection{Daily social or recreation time budget}

Regarding engagement in social and recreation activities, being in couple or having young children at home has a negative effect while being a worker has a positive effect. Car 
ownership and proximity to the high speed road network has also a positive effect, while it is negative for proximity to public transport. Only in the two cities of Grenoble and Strasbourg is found a significant and positive effect on activity engagement. This can be related with some immeasurable specificities of lifestyle in these two cities.

As for time budget devoted to social or recreation activity men have slightly longer activity time budget, while being in couple and the presence of children of age under 12 have inverse effect. Older people (over 65) have longer activity time budget, and, here again, workers have lower social-recreation time budget probably due to less available personal time.

Regarding spatial and transport availability characteristics, only distance to public transport plays a significant role: it induces slightly more time spent in social and recreation activity. For city-specific effects, in all French and Swiss cities (but with lower significance in this last case) people spend less time on social and recreation activity when compared with Brussels.

To sum up, the impact of spatial context and transport supply on daily travel time budget is limited: car ownership is linked to a higher probability to travel and travel time budget is slightly positively influenced by the distance to a high-speed road network. Regarding work time budget the main effect of transport is channelled through car ownership. The most prominent role is played by socio-demographic factors whether for travel time budget or different out-of-home activity time budgets. In parallel city (or country) specific effects play a noticeable role in activity time budgets, especially for work and shopping or personal business activity, and to a lesser extent for travel time budget. This may reflect spatial characteristics not yet considered in our data or cultural and lifestyle differences specific to each city.

\subsection{Trip duration per activity for city and transport mode contexts}

In this section, we investigate city, spatial and transport mode effects on trip duration for each of activity purposes. Since we are interested in investigating intrinsic mode-specific effect on travel duration, the averaged travel time per activity per day is not appropriate for this purpose. Trip duration per activity is calculated as the difference between its arrival time and departure time according to the type of activity conducted at its destination.

As for the specification of covariates, besides the same socio-demographic variables as previously with an added country effect, it is conducted in terms of city, transport mode and their interaction which aims to investigate the cross-effects of these two factors. We also add density as an indicator of proximity to destinations: we expect that the higher the density, the lower the distances to be travelled to reach amenities and the lower the duration of trips.

A standard Cox $\mathrm{PH}$ model is estimated for trip duration for each activity purpose. The selection of covariates in each of the final models is based on the stepwise model selection process. The Cox model estimation is performed by the Proc Phreg in SAS. As there are numerous tied duration data, the Efron method is applied to approximate the partial-likelihood (Efron, 1977).

The parameters estimation results are shown in Table 5.

First of all, the level of density has a significant impact on trip duration whether whatever the purpose or specifically for shopping / personal business and social / recreation activities: however, the coefficient is unexpectedly negative. This means that, controlling for mode, the higher the density the longer trip duration. This can be seen as the result of two opposite effects, the one exerted by spatial proximity to amenities, the other by congestion following from density, the second one being stronger. 
The country-specific effect is significant in some cases regarding trip duration. Indeed, in France trip duration is shorter when all purposes are considered together, and especially for school and social / recreation trips. On the opposite trip duration is longer in Switzerland for shopping / personal business trips. There is no specific effect for work trip duration for any country and no effect for Brussels (and Belgium) whatever the purpose. Because of these various directions of results according to the various trip purposes there is no obvious indication of any survey methodology effect. These differences could rather be attributed to overall urban and transport policy in the two countries, e.g. transport infrastructure investments in France having favoured travel speed by car until recent years.

Since the socio-demographic variables relate here to trip duration for various purposes, we should find here more detailed view of their impact when compared with the previous model of travel time budget (see first column of Table 4). Male travellers have a longer trip duration, whether considering overall purposes, work purpose or shopping / personal business purpose: this is consistent with their higher travel time budget. Youngsters under 15 have shorter trip durations (and shorter travel time budget). Youngsters between 15 and 25 have shorter trip durations for school and shopping / personal business purposes but longer travel time budget: they may compensate by more trips overall. On the opposite, older people (over 55) have longer trip durations whatever the trip purpose but shorter travel time budget: they may compensate by fewer trips overall. Results regarding presence of young children and work status are similar when comparing trip durations and travel time budget. 
Table 5: Cox proportional hazard models for trip duration per activity in city and transport mode contexts

\begin{tabular}{|c|c|c|c|c|c|}
\hline Covariates & All & Work & School & $\begin{array}{c}\text { Shopping / } \\
\text { Personal business }\end{array}$ & Social / Recreation \\
\hline Density & $-0.008 * * *$ & & & $-0.014 * * *$ & $-0.011 * * *$ \\
\hline \multicolumn{6}{|l|}{ Country-specific variables } \\
\hline France & $0.188 * * *$ & & $0.523 * * *$ & & $0.301 * * *$ \\
\hline Swiss & & & & $-0.341 * * *$ & \\
\hline \multicolumn{6}{|c|}{ Socio-demographic characteristics } \\
\hline Gender & $-0.096 * * *$ & $-0.129 * * *$ & & $-0.042 * * *$ & \\
\hline Age $<15$ & $0.248 * * *$ & n.a. & $0.557 * * *$ & $0.103 * * *$ & $0.176^{* * *}$ \\
\hline Age15_25 & & & $0.142 * *$ & 0.038 & \\
\hline Age25_55 & & & & & $-0.065 * * *$ \\
\hline Age55_65 & $-0.040 * * *$ & & & $-0.049 * *$ & $-0.167 * * *$ \\
\hline Age $\geq 65$ & $-0.067 * * *$ & n.a. & n.a. & & $-0.240 * * *$ \\
\hline Couple & & $0.031 *$ & $-0.046^{*}$ & & \\
\hline Children_12 & $0.141 * * *$ & & $0.203 * * *$ & $0.079 * * *$ & $0.087 * * *$ \\
\hline Work_status & & & & $0.064 * * *$ & $0.181 * * *$ \\
\hline \multicolumn{6}{|l|}{ City-specific variables } \\
\hline Grenoble & $-0.031 * *$ & $-0.091 * * *$ & & $0.084 * * *$ & \\
\hline \multicolumn{6}{|l|}{ Rennes } \\
\hline Strasbourg & & & $-0.139 * * *$ & & \\
\hline Lyon & $-0.221 * * *$ & $-0.187 * * *$ & $-0.370 * * *$ & $-0.106 * * *$ & \\
\hline \multicolumn{6}{|l|}{ Brussels } \\
\hline Geneva & & & $0.663 * * *$ & & \\
\hline Bern & & & & & $0.277 * * *$ \\
\hline Zurich & $-0.182 * * *$ & $-0.189 * * *$ & & & \\
\hline \multicolumn{6}{|l|}{ Transport modes } \\
\hline Walk & & $0.930 * * *$ & & & \\
\hline Bicycle & & $0.490 * * *$ & & $-0.193 * * *$ & \\
\hline Public transport & $-0.931 * * *$ & $-0.756 * * *$ & $-1.300 * * *$ & $-1.223 * * *$ & $-0.644 * * *$ \\
\hline Car & $-0.256^{* * *}$ & & $-0.181 * * *$ & $-0.570 * * *$ & \\
\hline \multicolumn{6}{|c|}{ Interaction effects of city and transport mode } \\
\hline Grenoble $\times$ Walk & $0.434 * * *$ & $0.244 * * *$ & 0.063 & & $0.625 * * *$ \\
\hline \multicolumn{6}{|l|}{ Grenoble $\times$ Bicycle } \\
\hline \multicolumn{6}{|l|}{$\begin{array}{l}\text { Grenoble } \times \text { Public } \\
\text { transport }\end{array}$} \\
\hline Grenoble $\times$ Car & & & $-0.284 * * *$ & & \\
\hline Rennes $\times$ Walk & $0.277 * * *$ & & & & $0.445 * * *$ \\
\hline Rennes $\times$ Bicycle & & & $-0.160 *$ & & $0.278 * * *$ \\
\hline $\begin{array}{l}\text { Rennes } \times \text { Public } \\
\text { transport }\end{array}$ & $-0.125 * * *$ & & $-0.208 * * *$ & & \\
\hline Rennes $\times$ Car & & & & $0.137 * * *$ & $-0.093 * * *$ \\
\hline Strasbourg $\times$ Walk & $0.255^{* * *}$ & & & & $0.474 * * *$ \\
\hline Strasbourg $\times$ Bicycle & & $-0.204 * *$ & & & $0.169 * * *$ \\
\hline $\begin{array}{l}\text { Strasbourg } \times \text { Public } \\
\text { transport }\end{array}$ & $-0.196 * * *$ & & $-0.188 * *$ & & \\
\hline Strasbourg $\times$ Car & & & & $0.122 * * *$ & \\
\hline Lyon $\times$ Walk & $0.404 * * *$ & & & & $0.510 * * *$ \\
\hline Lyon $\times$ Bicycle & & & & $-0.316^{*}$ & \\
\hline Lyon $\times$ Public transport & & & & & $-0.080 * * *$ \\
\hline Lyon $\times$ Car & $-0.057 * *$ & $-0.233 * * *$ & & & $-0.223 * * *$ \\
\hline Brussels $\times$ Walk & $0.100 * *$ & & $0.320 * *$ & $-0.354 * * *$ & $0.240 * * *$ \\
\hline
\end{tabular}




\begin{tabular}{|c|c|c|c|c|c|}
\hline \multicolumn{6}{|l|}{$\overline{\text { Brussels } \times \text { Bicycle }}$} \\
\hline $\begin{array}{l}\text { Brussels } \times \text { Public } \\
\text { transport }\end{array}$ & & & & & $0.312^{* * *}$ \\
\hline Brussels $\times$ Car & & $-0.315 * * *$ & & & \\
\hline Geneva $\times$ Walk & & $-0.286 * * *$ & & & \\
\hline \multicolumn{6}{|l|}{ Geneva $\times$ Bicycle } \\
\hline $\begin{array}{l}\text { Geneva } \times \text { Public } \\
\text { transport }\end{array}$ & & & $-0.334 * * *$ & $0.227 * * *$ & $0.165^{* * *}$ \\
\hline Geneva $\times$ Car & & & $-0.427 * * *$ & & \\
\hline Bern $\times$ Walk & $-0.180 * * *$ & & & & $-0.474 * * *$ \\
\hline Bern $\times$ Bicycle & $0.182 * * *$ & $0.223^{* *}$ & $0.396^{* *}$ & & \\
\hline \multicolumn{6}{|c|}{ Bern $\times$ Public transport } \\
\hline Bern $\times$ Car & $0.075^{* * *}$ & & & $0.202 * * *$ & $-0.197 * * *$ \\
\hline Zurich $\times$ Walk & & & & & $-0.134 * * *$ \\
\hline Zurich $\times$ Bicycle & $0.233 * * *$ & $0.464 * * *$ & $0.515 * * *$ & $0.410 * * *$ & \\
\hline \multicolumn{6}{|l|}{$\begin{array}{l}\text { Zurich } \times \text { Public } \\
\text { transport }\end{array}$} \\
\hline Zurich $\times$ Car & $0.103 * * *$ & & & & \\
\hline Sample size & 80807 & 18723 & 9838 & 18385 & 16620 \\
\hline Log-likelihood & $-824748,5$ & - & $-78426,08$ & $-160719,535$ & $-143479,575$ \\
\hline $\begin{array}{l}\text { Likelihood ratio } \\
\text { (df) }\end{array}$ & $\begin{array}{r}15111.02 * * * \\
(25)\end{array}$ & $\begin{array}{r}163458,015 \\
4024.97 * * * \\
(15)\end{array}$ & $\begin{array}{r}4384.17 * * * \\
(20)\end{array}$ & $\begin{array}{r}2857.90 * * * \\
(20)\end{array}$ & $\begin{array}{r}2850.76^{* * * *} \\
(25)\end{array}$ \\
\hline
\end{tabular}

As for the joint effect of city and transport mode, it is calculated as the summation of coefficients with respect to the city-specific, mode-specific and the cross-effect of city and transport modes. To ease the analysis, the joint (interaction) effects with respect to each of activity purposes are plotted in Figure 1 to Figure 5. The abscissa shows from left to right the increasing level of coefficient of the Cox model, which means a decreasing trip duration.

When considering trip duration for activities all purposes considered together (see Figure 1), it is interesting to find that the travel time by car is less than that of public transport for all cities. This implies that in these cities, private car is more competitive than public transport in terms of travel time for work. Then bicycle and walk have, as expected, shorter travel times, but not so different from car travel time. Overall there is a hierarchy between modes which broadly speaking is valid whatever the city.

Within this mode hierarchy Zurich and Lyon have longer trip duration by car and by public transport (with Strasbourg). We find again Lyon with longer trip duration by bicycle. The Swiss cities of Bern and Zurich have also the longest trip duration by walk. 


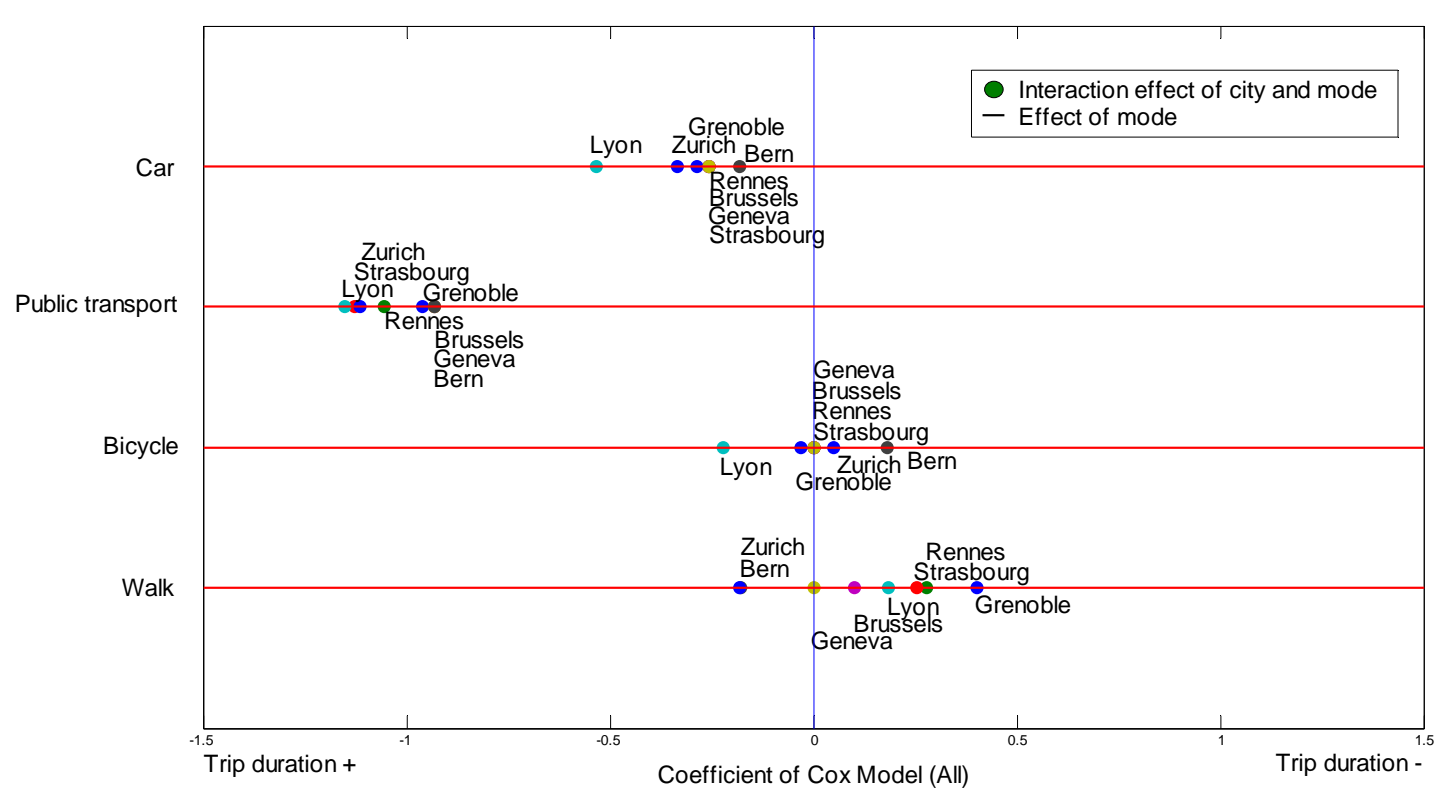

Figure 1: City and transport mode effects on trip duration for all activities

Considering now only work/training activity (see Figure 2), the hierarchy between modes is more obvious. Workers spend the most time on public transport to go to work, and especially in Zurich and Lyon. By car they spend less time when compared with public transport, and here again Lyon and Zurich with Brussels and Grenoble appear to have longer work trip duration by car compared with other cities. 


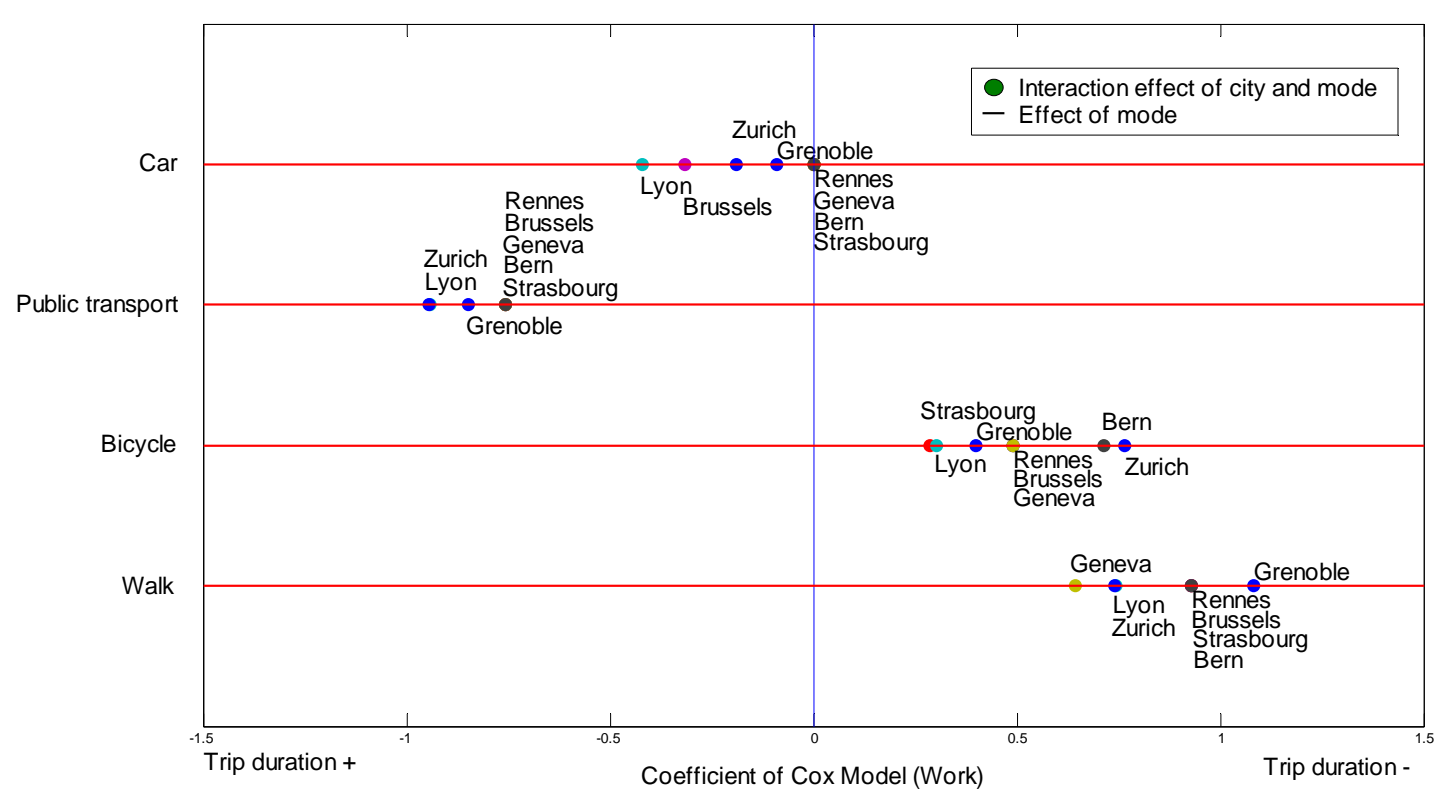

Figure 2: City and transport mode effects on trip duration for work activity

For school activity (see Figure 3), the results indicate that travel time by car is close to the travel time by walk and bicycle but definitely shorter than those by public transport.

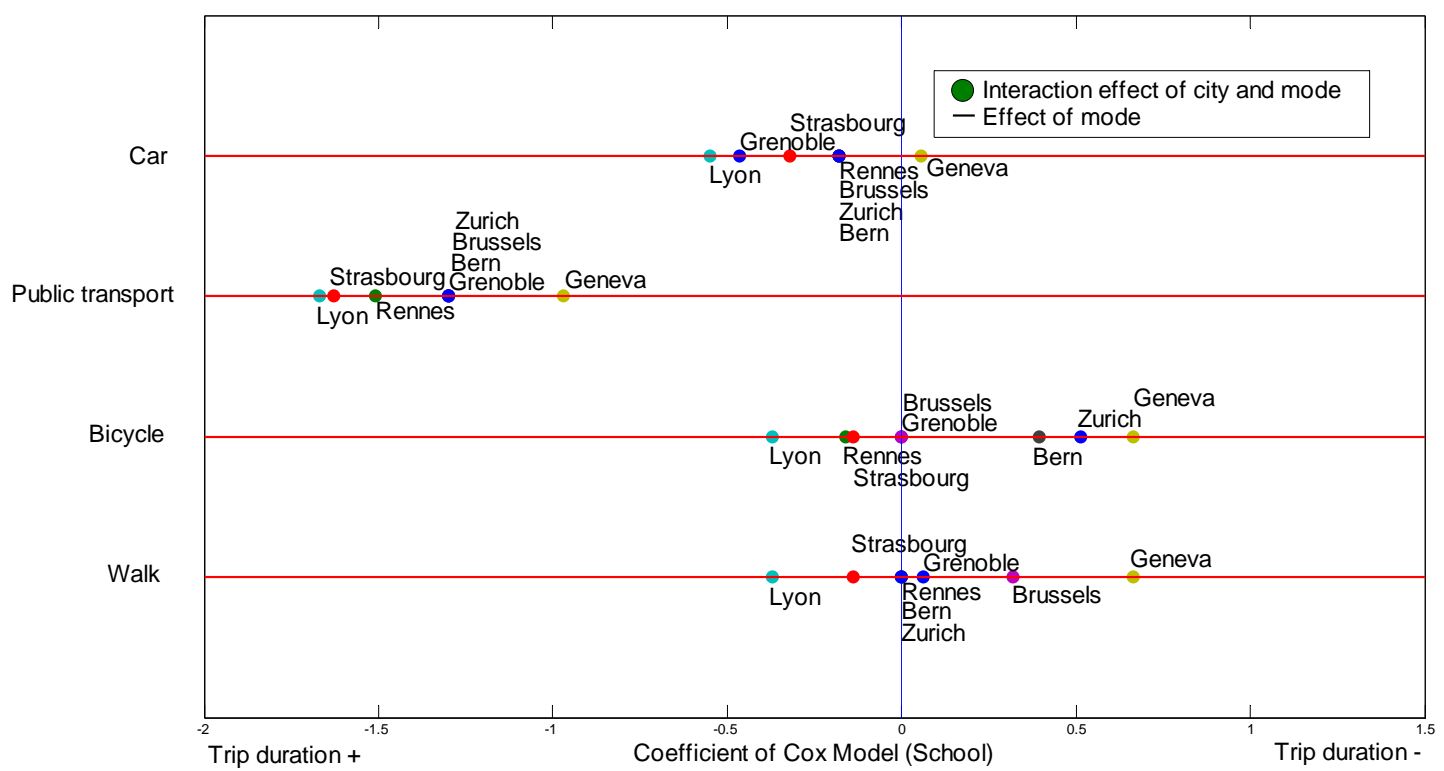

Figure 3: City and transport mode effects on trip duration for school activity 
Regarding shopping/personal business and social-recreation activities (see Figure 4 and Figure 5) the hierarchy between modes is much less obvious, despite public transport has still the longer trip durations. Moreover, there are much larger differences between cities when compared with other trip purposes, especially regarding bicycle and walk mode. This probably reflects specificities in urban settings and lifestyles along these various cities.

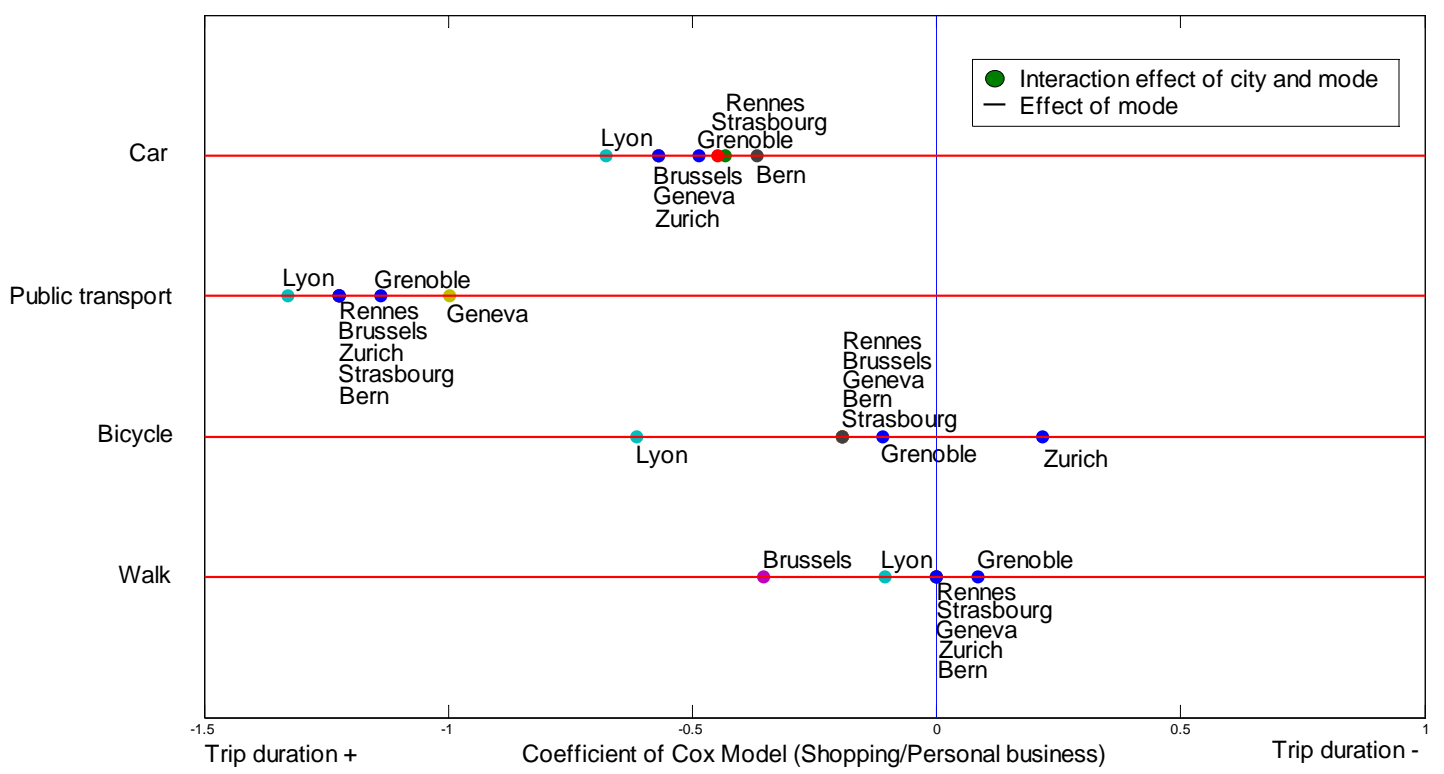

Figure 4: City and transport mode effects on trip duration for shopping/personal business activity 


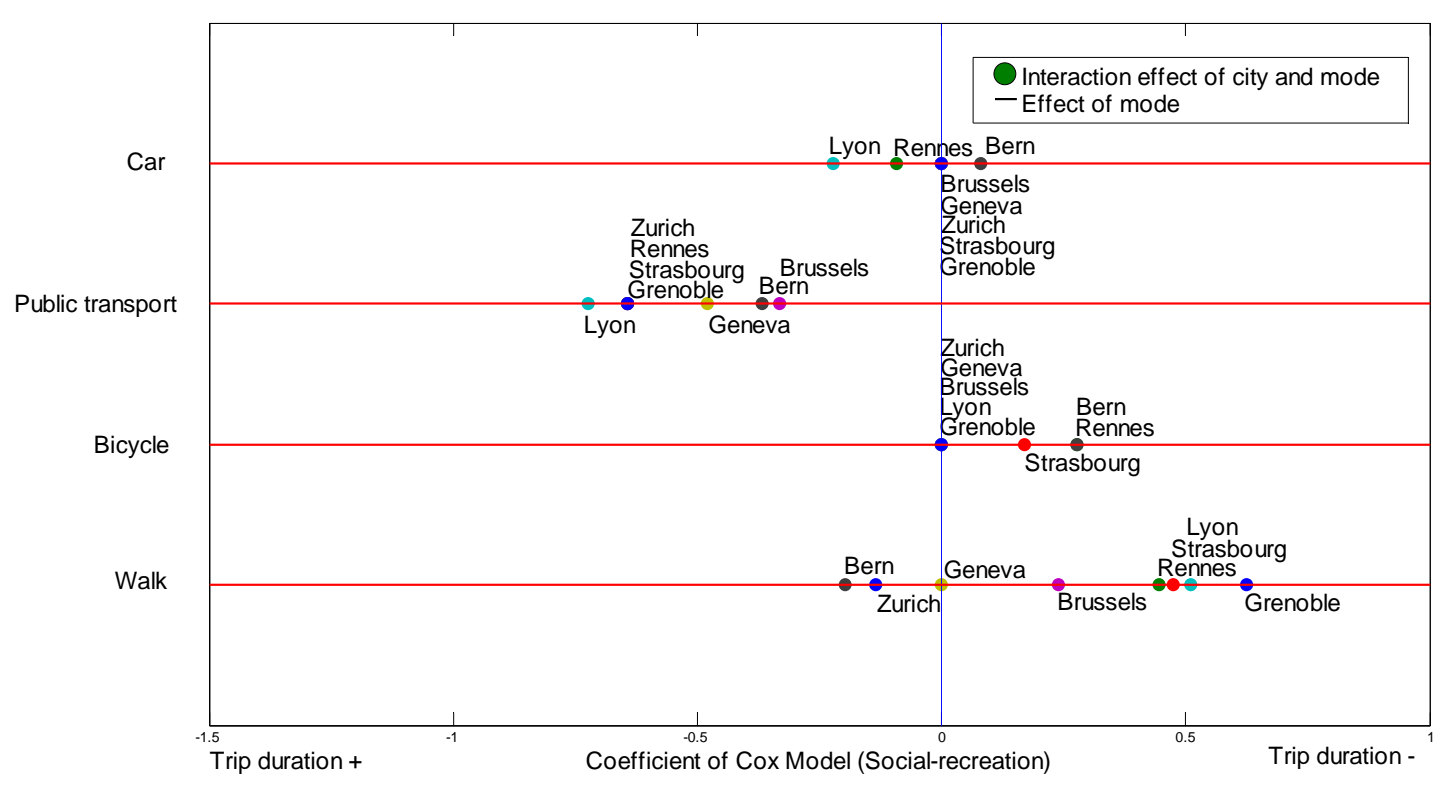

Figure 5: City and transport mode effects on trip duration for social-recreation activity

\section{Conclusion}

In this study, we analyze the effects of socio-demographic characteristics, spatial context, transport supply and city-specific effects on daily travel time budget, daily out-of-home activity time budgets and trip duration for each of activity purposes across eight cities in France, Belgium and Switzerland. A particular effort has been achieved in order to harmonize the data. Unlike previous literature, analysis is performed at the individual level, while spatial context (density) and transport supply indicators have been measured with common definition and methodology.

The results indicate that socio-demographic and city-specific characteristics play a major role while residential density and proximity to high level road or public transport networks have a very limited impact on time budgets for travel and out-of-home activities. These results are somewhat in line with previous work on this topic (Timmermans et al, 2002). Obviously caution should be kept in mind when comparing data collected in various countries and cultural areas with different survey tools. However, given our efforts to check and harmonize these sources and build a common methodology, jointly with an individual-based analysis, our conclusions strengthen the case: they confirm the minor impact of spatial context and transport supply, as measured in our study, on travel and activity time allocation when compared with socio-demographic and city (and sometimes country or cultural area) specific characteristics.

Regarding trip duration, residential density has an unexpected increasing effect: the higher the density, the longer trip duration. This is interpreted as the result of two opposite effects, the one exerted by spatial proximity to amenities, the other by congestion following from density, the second one being stronger. When it comes to mode-specific trip duration, the first distinction is between public transport (with longer travel times) and other modes of transport 
which have similar travel times, except for work activity for which the car is associated with intermediate travel times. Then, within this basic difference between modes, come only some city-specific differences reflecting cities own urban and transport policy.

\section{Acknowledgements}

This research has benefited from a grant of ANR (the French Agency for Research, Project EuroCities-DATTA n ${ }^{\circ}$ ANR-07-BLAN-0032-01). The help of Xavier Pauly at GRT (Namur) and Pierre Dessemontet at LASUR (Lausanne) for gathering data on transport supply respectively on Brussels and the three Swiss cities is gratefully acknowledged.

\section{Reference}

Bhat, C. (1996) A generalized multiple durations proportional hazard model with an application to activity behavior during the evening work-to-home commute. Transportation Research B 30(6), 465-480

Corbière, F., Joly, P. (2007) A SAS macro for parametric and semiparametric mixture cure models. Computer Methods and Programs in Biomedicine 85, 173-180.

Cox, D.R. (1972) Regression Models and Life Tables. Journal of the Royal Statistical Society $B, 34,187-200$.

Efron., B. (1977) The Efficiency of Cox's Likelihood Function for Censored Data. Journal of the American Statistical Association, 72, 557-565.

Eurostat (2003) Time use at different stages of life - Results from 13 European countries, Rapport de recherche, Publication Officielle de la Communauté Europeenne, Luxembourg, 77 p.

Joly, I., Kaufmann, V, Littlejohn, K. (2007) La croissance des budgets-temps de transport en question: nouvelles approches. Rapport final de recherche, Programme Français de Recherche et d'Innovation dans les Transports Terrestres (PREDIT), Groupe Opérationnel $\mathrm{n}^{\circ} 1$, « Mobilité, territoires et développement durable » (2005-2006).

Joly, I. (2006) Stability of regularity of the daily travel time in Lyon? Application of a duration model. International Journal of Transport Economics, XXXIII, vol. 3, 369-400.

Kalbfleisch, J.D., Prentice, R.L. (2002) The Statistical Analysis of Failure Time Data. New York: John Wiley \& Sons. Inc. $2^{\text {nd }}$ Edition.

Kitamura, R., Robinson, J., Golob, T.F., Bradley, M., Leonard, J., van der Hoorn, T. (1992) A comparative analysis of time use data in the Netherlands and California. Report UCD-ITSRR-92-9, Institute of Transportation Studies, University of California

Levinson, D.M. (1999) Space, money, life-stage, and the allocation of time. Transportation 26(2), 141-171.

Ma, T.Y., Raux, C., Cornelis, E., Joly, I. (2009) Multi-state non-homogeneous semi-markov model of daily activity type, timing and duration sequence. Transportation Research Record, no. 2134, 123-134.

MOBEL, Belgian Mobility Survey Web Site. http://www.mobel.be/ (30 Dec. 09) 
Mokhtarian P.L., Chen, C. (2004) TTB or not TTB, that is the question: A review and analysis of the empirical literature on travel time (and money) budgets. Transportation Research Part A, 38, 643-675.

Oakes, D. (1977) The asymptotic information in censored survival data. Biometrika 64, 441448.

Openshaw, S. (1984) The modifiable areal unit problem. Concepts and Techniques in Modern Geography 38, 41 p., Geo Books, Norwich, UK.

Office fédéral de la statistique (2001) La mobilité en Suisse, Résultats du micro-recensement 2000 sur le comportement de la population en matière de transports. Berne et Neuchâtel.

Timmermans H., van der Waerden P., Alves M., Polak J., Ellis S., Harvey A.S., Kurose S., Zandee R. (2002) Time allocation in urban and transport settings: an international, inter-urban perspective. Transport Policy, 9(2),79-93.

Timmermans H., van der Waerden P., Alves M., Polak J., Ellis S., Harvey A.S., Kurose S., Zandee R. (2003) Spatial context and the complexity of daily travel patterns: an international comparison. Journal of Transport Geography, 11, 37-46. 


\section{Appendixes}

6.1 Appendix A. Classification of initial trip purposes for the eight cities

\begin{tabular}{|c|c|c|c|}
\hline & $\begin{array}{l}\text { Grenoble, Rennes, } \\
\text { Strasbourg, Lyon }\end{array}$ & Brussels & Geneva, Bern, Zurich \\
\hline \multirow[t]{2}{*}{ Work } & usual work & work, visit for work & work, training, \\
\hline & non usual work & & \\
\hline School & $\begin{array}{l}\text { nursery school, primary } \\
\text { school, second school, } \\
\text { university }\end{array}$ & school & school \\
\hline $\begin{array}{l}\text { Shopping/personal } \\
\text { business }\end{array}$ & $\begin{array}{l}\text { daily/weekly purchase, } \\
\text { looking for a job, } \\
\text { administration, health, } \\
\text { purchase of equipment, } \\
\text { clothing or leisure }\end{array}$ & $\begin{array}{l}\text { daily/weekly purchase, } \\
\text { shopping, personal business }\end{array}$ & $\begin{array}{l}\text { daily purchase, shopping, } \\
\text { personal business, service }\end{array}$ \\
\hline Social-recreation & $\begin{array}{l}\text { walk, sports, culture and } \\
\text { associative activities, out- } \\
\text { of-home eating, visit to the } \\
\text { family or to friends }\end{array}$ & $\begin{array}{l}\text { walk, sports, culture and } \\
\text { leisure activities, out-of- } \\
\text { home eating, visit to the } \\
\text { family or to friends }\end{array}$ & leisure \\
\hline Accompany & accompany & deposit or seek someone & accompany \\
\hline
\end{tabular}

\subsection{Appendix B. Average individual daily travel time budget across cities}

\begin{tabular}{|c|c|c|c|c|c|c|c|c|c|c|}
\hline & & & Grenoble & Rennes & Strasbourg & Lyon & Brussels & Geneva & Bern & Zurich \\
\hline \multirow{5}{*}{$\begin{array}{c}\text { Daily } \\
\text { travel } \\
\text { time } \\
\text { budget }\end{array}$} & \multirow{2}{*}{ without zero } & mean & 69.3 & 62.2 & 69.8 & 71.6 & 68.9 & 73.7 & 69.8 & 74.6 \\
\hline & & s.d. & 49.2 & 47.5 & 49.3 & 52.0 & 52.7 & 62.8 & 57.7 & 62.9 \\
\hline & \multirow{2}{*}{ with zero } & mean & 58.3 & 53.1 & 59.1 & 60.0 & 57.1 & 65.8 & 62.4 & 66.8 \\
\hline & & s.d. & 51.7 & 49.1 & 51.8 & 54.4 & 54.5 & 63.5 & 58.6 & 63.8 \\
\hline & $\%>0$ & & $84.1 \%$ & $85.3 \%$ & $84.7 \%$ & $83.7 \%$ & $83.0 \%$ & $89.3 \%$ & $89.4 \%$ & $89.5 \%$ \\
\hline
\end{tabular}




\subsection{Appendix C. Average individual daily travel time budget per activity purpose (in minutes)}

\begin{tabular}{|c|c|c|c|c|c|c|c|c|c|c|c|c|c|c|c|c|c|c|c|c|c|c|c|c|c|}
\hline \multirow{2}{*}{\multicolumn{2}{|c|}{ Activity }} & \multicolumn{3}{|c|}{ Grenoble } & \multicolumn{3}{|c|}{ Rennes } & \multicolumn{3}{|c|}{ Strasbourg } & \multicolumn{3}{|c|}{ Lyon } & \multicolumn{3}{|c|}{ Brussels } & \multicolumn{3}{|c|}{ Geneva } & \multicolumn{3}{|c|}{ Bern } & \multicolumn{3}{|c|}{ Zurich } \\
\hline & & $\begin{array}{c}\% \\
>0 \\
\end{array}$ & $\begin{array}{c}\text { No } \\
\text { zero }\end{array}$ & $\begin{array}{l}\text { With } \\
\text { zero }\end{array}$ & $\begin{array}{r}\% \\
>0 \\
\end{array}$ & \begin{tabular}{|c} 
No \\
zero \\
\end{tabular} & $\begin{array}{l}\text { With } \\
\text { zero }\end{array}$ & $\begin{array}{r}\% \\
>0 \\
\end{array}$ & \begin{tabular}{|c|} 
No \\
zero \\
\end{tabular} & $\begin{array}{l}\text { With } \\
\text { zero }\end{array}$ & $\begin{array}{r}\% \\
>0 \\
\end{array}$ & $\begin{array}{c}\text { No } \\
\text { zero }\end{array}$ & $\begin{array}{l}\text { With } \\
\text { zero }\end{array}$ & $\begin{array}{r}\% \\
>0 \\
\end{array}$ & \begin{tabular}{|c|} 
No \\
zero \\
\end{tabular} & $\begin{array}{l}\text { With } \\
\text { zero }\end{array}$ & $\begin{array}{r}\% \\
>0 \\
\end{array}$ & $\begin{array}{c}\text { No } \\
\text { zero }\end{array}$ & $\begin{array}{l}\text { With } \\
\text { zero }\end{array}$ & $\begin{array}{r}\% \\
>0 \\
\end{array}$ & \begin{tabular}{|c|} 
No \\
zero \\
\end{tabular} & $\begin{array}{l}\text { With } \\
\text { zero }\end{array}$ & $\begin{array}{r}\% \\
>0 \\
\end{array}$ & $\begin{array}{c}\text { No } \\
\text { zero }\end{array}$ & $\begin{array}{l}\text { With } \\
\text { zero }\end{array}$ \\
\hline \multirow[t]{2}{*}{ Work } & mean & 38 & 31.7 & 12.1 & 40 & 30.0 & 11.9 & 42 & 31.2 & 13.1 & 40 & 35.5 & 14.3 & 41 & 34.6 & 14.2 & 47 & 28.2 & 13.1 & 42 & 27.7 & 11.7 & 44 & 30.6 & 13.5 \\
\hline & s.d. & & 30.1 & 24.1 & & 33.7 & 25.8 & & 34.1 & 26.9 & & 33.4 & 27.5 & & 36.3 & 28.8 & & 34.8 & 27.6 & & 34.6 & 26.3 & & 30.1 & 25.1 \\
\hline \multirow[t]{2}{*}{ School } & mean & 28 & 22.9 & 6.3 & 28 & 20.3 & 5.7 & 25 & 22.5 & 5.7 & 22 & 22.4 & 4.9 & 19 & 19.1 & 3.7 & 14 & 21.2 & 2.9 & 9 & 19.7 & 1.7 & 11 & 22.8 & 2.5 \\
\hline & s.d. & & 18.8 & 14.2 & & 15.9 & 12.4 & & 15.6 & 12.5 & & 17.8 & 12.4 & & 17.7 & 10.9 & & 17.1 & 9.6 & & 14.5 & 6.9 & & 20.4 & 9.8 \\
\hline \multirow{2}{*}{$\begin{array}{l}\text { Shopping / } \\
\text { Personal } \\
\text { business }\end{array}$} & mean & 41 & 20.3 & 8.4 & 40 & 18.3 & 7.4 & 44 & 20.1 & 8.9 & 39 & 22.5 & 8.7 & 45 & 21.4 & 9.7 & 44 & 24.2 & 10.7 & 54 & 20.9 & 11.2 & 48 & 22.0 & 10.4 \\
\hline & s.d. & & 18.2 & 15.4 & & 18.1 & 14.6 & & 17.7 & 15.4 & & 21.5 & 17.3 & & 20.0 & 17.1 & & 38.9 & 28.6 & & 23.2 & 19.9 & & 31.7 & 24.4 \\
\hline \multirow{2}{*}{$\begin{array}{l}\text { Social- } \\
\text { Recreation }\end{array}$} & mean & 43 & 22.0 & 9.5 & 37 & 21.1 & 7.8 & 42 & 22.2 & 9.4 & 36 & 23.6 & 8.5 & 37 & 30.9 & 11.6 & 55 & 33.9 & 18.8 & 52 & 32.7 & 17.0 & 54 & 33.7 & 18.0 \\
\hline & s.d. & & 26.0 & 20.2 & & 23.8 & 17.6 & & 22.6 & 18.3 & & 23.6 & 18.1 & & 33.0 & 25.1 & & 45.2 & 37.6 & & 39.3 & 32.7 & & 40.5 & 34.1 \\
\hline \multirow[t]{2}{*}{ Accompanying } & mean & 21 & 21.7 & 4.5 & 18 & 20.2 & 3.6 & 18 & 21.4 & 3.7 & 18 & 23.5 & 4.3 & 20 & 23.3 & 4.6 & 6 & 16.4 & 1.0 & 2 & 12.1 & 0.3 & 2 & 16.0 & 0.3 \\
\hline & s.d. & & 19.8 & 12.6 & & 17.8 & 10.8 & & 17.1 & 10.8 & & 21.2 & 12.8 & & 26.8 & 15.0 & & 12.8 & 5.0 & & 8.8 & 2.3 & & 12.8 & 2.9 \\
\hline
\end{tabular}


6.4 Appendix D. Average travel time by trip and by mode for all cities (in minutes)

\begin{tabular}{|c|c|c|c|c|c|c|c|c|c|c|c|c|c|c|c|c|}
\hline \multirow[b]{2}{*}{ Mode* } & \multicolumn{2}{|l|}{ Grenoble } & \multicolumn{2}{|l|}{ Rennes } & \multicolumn{2}{|l|}{ Strasbourg } & \multicolumn{2}{|l|}{ Lyon } & \multicolumn{2}{|l|}{ Brussels } & \multicolumn{2}{|l|}{ Geneva } & \multicolumn{2}{|l|}{ Bern } & \multicolumn{2}{|l|}{ Zurich } \\
\hline & mean & s.d. & mean & s.d. & mean & s.d. & mean & s.d. & mean & s.d. & mean & s.d. & mean & s.d. & mean & s.d. \\
\hline Walk & 9.1 & 9.2 & 9.8 & 8.6 & 9.6 & 7.4 & 12.5 & 14.2 & 9.1 & 9.2 & 15.0 & 23.7 & 16.8 & 24.1 & 16.8 & 27.0 \\
\hline Bicycle & 12.5 & 10.6 & 12.0 & 10.3 & 12.7 & 15.8 & 15.4 & 21.1 & 12.5 & 10.6 & 14.5 & 19.0 & 11.9 & 11.7 & 13.5 & 16.1 \\
\hline $\begin{array}{l}\text { Public } \\
\text { transport }\end{array}$ & 27.7 & 21.1 & 28.1 & 16.0 & 31.9 & 24.3 & 31.3 & 21.9 & 27.7 & 21.1 & 31.8 & 29.1 & 31.9 & 22.0 & 37.8 & 28.4 \\
\hline Car & 15.5 & 14.9 & 14.9 & 16.4 & 14.8 & 14.0 & 17.7 & 19.1 & 15.5 & 14.9 & 18.3 & 26.3 & 17.4 & 30.8 & 19.7 & 29.7 \\
\hline
\end{tabular}

* For multimodal trips, one main mode is assigned the total travel time for the entire trip according to the following priority: public transport $>$ car $>$ bicycle $>$ walk 


\subsection{Appendix E. Average out-of-home activity time budgets per person per day (in minutes)}

\begin{tabular}{|c|c|c|c|c|c|c|c|c|c|c|c|c|c|c|c|c|c|c|c|c|c|c|c|c|c|}
\hline \multirow{2}{*}{\multicolumn{2}{|c|}{$\mathrm{C}_{\text {Activity }}^{\text {City }}$}} & \multicolumn{3}{|c|}{ Grenoble } & \multicolumn{3}{|c|}{ Rennes } & \multicolumn{3}{|c|}{ Strasbourg } & \multicolumn{3}{|c|}{ Lyon } & \multicolumn{3}{|c|}{ Brussels } & \multicolumn{3}{|c|}{ Geneva } & \multicolumn{3}{|c|}{ Bern } & \multicolumn{3}{|c|}{ Zurich } \\
\hline & & \multirow{2}{*}{\begin{tabular}{c|c}
$\%$ \\
$>0$
\end{tabular}} & \multirow{2}{*}{$\begin{array}{r}\text { no zero } \\
474 \\
\end{array}$} & \multirow{2}{*}{\begin{tabular}{r|} 
with \\
zero \\
179 \\
\end{tabular}} & \multirow{2}{*}{\begin{tabular}{r|}
$\%$ \\
$>0$ \\
39 \\
\end{tabular}} & \multirow{2}{*}{\begin{tabular}{|c|} 
no \\
zero \\
487 \\
\end{tabular}} & \multirow{2}{*}{\begin{tabular}{|r|} 
with \\
zero
\end{tabular}} & \multirow{2}{*}{\begin{tabular}{r|}
$\%$ \\
$>0$ \\
41 \\
\end{tabular}} & \multirow{2}{*}{\begin{tabular}{|c|} 
no \\
zero \\
473 \\
\end{tabular}} & \multirow{2}{*}{\begin{tabular}{|r|} 
with \\
zero \\
194 \\
\end{tabular}} & \multirow{2}{*}{\begin{tabular}{|c|}
$\%$ \\
$>0$ \\
40 \\
\end{tabular}} & \multirow{2}{*}{\begin{tabular}{|c|}
$\begin{array}{c}\text { no } \\
\text { zero }\end{array}$ \\
481 \\
\end{tabular}} & \multirow{2}{*}{\begin{tabular}{|r|}
$\begin{array}{r}\text { with } \\
\text { zero }\end{array}$ \\
192 \\
\end{tabular}} & \multirow{2}{*}{\begin{tabular}{|c|}
$\%$ \\
$>0$ \\
39 \\
\end{tabular}} & \multirow{2}{*}{\begin{tabular}{|c|} 
no \\
zero \\
461 \\
\end{tabular}} & \multirow{2}{*}{\begin{tabular}{|r|} 
with \\
zero
\end{tabular}} & \multirow{2}{*}{\begin{tabular}{|c|}
$\%$ \\
$>0$ \\
47 \\
\end{tabular}} & \multirow{2}{*}{\begin{tabular}{|c|}
$\begin{array}{c}\text { no } \\
\text { zero }\end{array}$ \\
463 \\
\end{tabular}} & \multirow{2}{*}{\begin{tabular}{|l|} 
with \\
zero \\
220 \\
\end{tabular}} & \multirow{2}{*}{\begin{tabular}{|c|}
$\%$ \\
$>0$ \\
41 \\
\end{tabular}} & $\begin{array}{c}\text { no } \\
\text { zero }\end{array}$ & $\begin{array}{l}\text { with } \\
\text { zero }\end{array}$ & $\begin{array}{r}\% \\
>0 \\
\end{array}$ & $\begin{array}{c}\text { no } \\
\text { zero }\end{array}$ & $\begin{array}{l}\text { with } \\
\text { zero }\end{array}$ \\
\hline Work (1) & mean & & & & & & & & & & & & & & & & & & & & 494 & 205 & 44 & 511 & 224 \\
\hline & s.d. & & 139 & 245 & & 129 & 251 & & 143 & 250 & & 138 & 251 & & 150 & 244 & & 175 & 261 & & 167 & 266 & & 165 & 276 \\
\hline School(2) & mean & 28 & 386 & 106 & 28 & 415 & 116 & 25 & 385 & 97 & 22 & 435 & 95 & 19 & 396 & 76 & 12 & 348 & 40 & 8 & 331 & 25 & 11 & 342 & 37 \\
\hline & s.d. & & 139 & 187 & & 136 & 200 & & 131 & 179 & & 115 & 187 & & 130 & 166 & & 119 & 118 & & 115 & 93 & & 119 & 113 \\
\hline Shopping/Pers & mean & 42 & 65 & 27 & 40 & 62 & 25 & 44 & 58 & 26 & 39 & 68 & 26 & 44 & 73 & 32 & 45 & 65 & 29 & 55 & 61 & 33 & 47 & 62 & 29 \\
\hline $\begin{array}{l}\text { onal business } \\
(3)\end{array}$ & s.d. & & 63 & 51 & & 63 & 50 & & 52 & 45 & & 68 & 54 & & 83 & 66 & & 86 & 66 & & 86 & 70 & & 92 & 70 \\
\hline Social- & mean & 43 & 153 & 65 & 36 & 146 & 53 & 42 & 154 & 65 & 36 & 156 & 55 & 33 & 182 & 60 & 53 & 159 & 84 & 49 & 155 & 76 & 50 & 151 & 76 \\
\hline Recreation (4) & s.d. & & 121 & 110 & & 125 & 103 & & 125 & 111 & & 126 & 106 & & 150 & 121 & & 135 & 126 & & 135 & 122 & & 141 & 125 \\
\hline Accompanyin & mean & 21 & 22 & 5 & 18 & 20 & 4 & 17 & 23 & 4 & 18 & 23 & 4 & 20 & 23 & 5 & 5 & 16 & 1 & 2 & 12 & 0 & 2 & 15 & 0 \\
\hline & s.d. & & 20 & 13 & & 17 & 11 & & 19 & 12 & & 21 & 13 & & 27 & 15 & & 12 & 5 & & 9 & 2 & & 11 & 2 \\
\hline Sum of (3.4.5) & mean & 74 & 131 & 96 & 69 & 118 & 82 & 73 & 130 & 94 & 67 & 128 & 86 & 68 & 141 & 96 & 78 & 147 & 114 & 81 & 134 & 109 & 78 & 134 & 105 \\
\hline & s.d. & & 120 & 118 & & 119 & 113 & & 121 & 118 & & 122 & 117 & & 144 & 136 & & 141 & 138 & & 135 & 133 & & 141 & 136 \\
\hline Sum of & mean & 99 & 384 & 382 & 99 & 392 & 389 & 99 & 390 & 385 & 99 & 375 & 373 & 96 & 370 & 354 & 100 & 375 & 373 & 100 & 340 & 339 & 100 & 368 & 366 \\
\hline( & s.d. & & 219 & 220 & & 216 & 218 & & 220 & 223 & & 220 & 221 & & 224 & 232 & & 242 & 242 & & 257 & 257 & & 259 & 259 \\
\hline
\end{tabular}

